\title{
Locally accelerated growth is part of the innate immune response and repair mechanisms in reef-building corals as detected by green fluorescent protein (GFP)-like pigments
}

\author{
C. D'Angelo $\cdot$ E. G. Smith $\cdot$ F. Oswald · \\ J. Burt $\cdot$ D. Tchernov $\cdot$ J. Wiedenmann
}

Received: 17 December 2011/ Accepted: 31 May 2012/Published online: 26 June 2012

(C) The Author(s) 2012. This article is published with open access at Springerlink.com

\begin{abstract}
Homologs of the green fluorescent protein (GFP) are a prevalent group of host pigments responsible for the green, red and purple-blue colours of many reefbuilding corals. They have been suggested to contribute to the striking coloration changes of different corals species in response to wounding and infestation with epibionts/parasites. In order to elucidate the physiological processes underlying the potentially disease-related colour changes, we have analysed spatial and temporal expression patterns of GFP-like proteins and other biomarkers in corals from the Red Sea, the Arabian/Persian Gulf and Fiji both in their natural habitat and under specific laboratory conditions. The expression of distinct GFP-like proteins and the growth marker proliferating cell nuclear antigen was
\end{abstract}

Communicated by Biology Editor Dr. Anastazia Banaszak

Electronic supplementary material The online version of this article (doi:10.1007/s00338-012-0926-8) contains supplementary material, which is available to authorized users.

C. D’Angelo · E. G. Smith · J. Wiedenmann $(\bowtie)$

National Oceanography Centre, Southampton (NOCS),

University of Southampton, European Way, SO143ZH

Southampton, UK

e-mail: joerg.wiedenmann@noc.soton.ac.uk

F. Oswald

Department of Internal Medicine I, Center for Internal Medicine, University Medical Center Ulm, Albert-Einstein-Allee 23, 89081 Ulm, Germany

J. Burt

Biology Department, New York University, Abu Dhabi, PO Box 129 188, Abu Dhabi, UAE

D. Tchernov

Department of Marine Biology, University of Haifa,

31905 Mt. Carmel, Israel upregulated in growing branch tips and margins of healthy coral colonies as well as in disturbed colony parts. Furthermore, phenoloxidase activity increased in these proliferating tissues. It is thus demonstrated that locally accelerated growth is part of the innate immune response and repair mechanisms in reef-building corals and, moreover, these processes can be detected utilizing the excellent biomarker properties of GFP-like proteins. Finally, the results of this work suggest an additional vulnerability of corals in predicted future scenarios of increased ocean acidification, warming and eutrophication that are anticipated to reduce coral growth capacity.

Keywords Green fluorescent protein (GFP) .

Coral disease - Immune response - Climate change ·

Coral parasite $\cdot$ Coral bleaching

\section{Introduction}

Shallow water coral reefs are among the most important centres of marine biodiversity providing invaluable ecosystem services to millions of people. A multiplicity of stressors such as global warming, ocean acidification, rising pollution and overfishing might result in a dramatic loss of coral reefs within this century (Hughes et al. 2003; Hoegh-Guldberg et al. 2007). Furthermore, several coral diseases have been described which represent a significant threat to coral reef survival (Rosenberg and Loya 2004). Most coral diseases are associated with deviations from the normal visual appearance, and hence their names are often inspired by the characteristic colour change. In some cases, the pigments of involved pathogens contribute to the alteration in the coral colour (Cooney et al. 2002; Rosenberg and Loya 2004), whereas in others, the loss of coral tissue and/or the symbiotic 
algae (zooxanthellae) is responsible for the colour change (Gladfelter 1982; Rosenberg and Loya 2004). GFP-like proteins were proposed to cause the colour changes of corals in response to wounding and infestation with epibionts referred to as the pink-blue spot syndrome (Bongiorni and Rinkevich 2005). While some authors interpret the pink/blue pigmentation of Porites sp. and Acropora sp. as a local response to stress (Bongiorni and Rinkevich 2005; Beeden et al. 2008; Benzoni et al. 2010), others link them to coral diseases (e.g. the pink-line syndrome of $P$. lutea; Ravindran and Raghukumar 2006) or the Porites trematodiasis (PorTrem; Aeby et al. 2011). Finally, the non-normal purple and red pigmentation has been associated with potential immune responses of Acropora millepora and Porites sp. (Palmer et al. 2008).

The pigments responsible for the pink-blue pigmentation of reef coral response belong to the family of GFP-like proteins (Dove et al. 2001; Wiedenmann et al. 2004b, 2009; Oswald et al. 2007; Alieva et al. 2008; D’Angelo et al. 2008). Based on their photophysical properties, they can be divided into two major groups: the fluorescent proteins (FPs), emitting photons in the spectral range from cyan to red upon stimulation with light of suitable wavelengths, and the non-fluorescent chromoproteins (CPs), which display bright purple to blue colours (Prescott et al. 2003; Alieva et al. 2008; Nienhaus and Wiedenmann 2009). The slow turnover (half-life $\sim 3$ weeks) associated with the stable $\beta$-can fold of GFP-like proteins facilitates the high-level accumulation in coral tissue (Leutenegger et al. 2007b; Oswald et al. 2007). GFP-like proteins are assumed to fulfil a photoprotective function in some anthozoans (Wiedenmann et al. 1999; Salih et al. 2000; Dove et al. 2001). This view is supported by the finding that expression of several FPs and CPs in reef corals is upregulated at the transcriptional levels in response to increased exposure to (blue) light (D'Angelo et al. 2008). However, results of molecular phylogenetic analyses of the protein sequences in combination with deviating regulation patterns suggest that distinct groups of GFP-like proteins might fulfil various functions among different taxonomic groups (Alieva et al. 2008; D'Angelo et al. 2008).

Fluorescent proteins (FPs) from reef corals and other anthozoans are routinely applied as markers in biomedical and pharmaceutical research applications, for instance, as reporters of gene activity in live-cell assays (Wiedenmann et al. 2004a, 2009; Kredel et al. 2009; Fuchs et al. 2010). They are favoured markers because their fluorescence can be easily detected and quantified due to the excellent signal-to-noise ratio (Wiedenmann et al. 2009).

In this study, we explored whether it is possible to utilize GFP-like proteins as intrinsic markers for diseases and stress in coral tissue by identifying physiological processes associated with potentially disease- and stress-related colour changes.
As an increased expression of GFP-like proteins is regularly found in growth zones such as apical polyps or colony edges of healthy corals (D'Angelo et al. 2008), we tested the hypothesis that the marker properties of the GFPlike proteins accumulated in disturbed areas can be exploited to correlate the pigmentation response of the pink-blue syndrome(s) of Porites sp and Acropora sp. with growth processes.

To this end, we conducted a thorough analysis of expression patterns of GFP-like proteins and the growth marker proliferating cell nuclear antigen (PCNA). The intranuclear PCNA is a well-conserved polypeptide that is synthesized mostly during the DNA synthesis phase of the cell cycle (Strzalka and Ziemienowicz 2011). Hence, it is used as growth marker in biomedical research to characterize quickly proliferating tissue, for instance, in tumours (Leonardi et al. 1992). As increased phenoloxidase (PO) activity was reported previously for pigmented coral tissue (Palmer et al. 2008), we assessed whether also PO activity might be indicative of growth zones. In our study, we focussed on four coral species to define the effects of colony morphology on the pigment and growth responses: Montipora foliosa (plate-like), Acropora pulchra/polystoma (branching) and Porites lobata (massive). To assess how common these pigment responses are among corals from different geographical regions, we studied specimens from the Red Sea, the Arabian/Persian Gulf and Fiji both in their natural habitat and under specific, controlled laboratory conditions.

\section{Materials and methods}

\section{Coral material}

Porites lobata samples were collected live from $4 \mathrm{~m}$ depth on Saadiyat reef in Abu Dhabi, United Arab Emirates (24 $35^{\prime} 56.4^{\prime \prime} \mathrm{N}, 54^{\circ} 25^{\prime} 17.4^{\prime \prime} \mathrm{E}$ ) in May 2010 and transported to the UK for cultivation in the experimental mesocosm of the Coral Reef Laboratory of the NOCS (http://www. noc.soton.ac.uk/corals/). The corals were kept in artificial sea water (salinity 42 ) at $27{ }^{\circ} \mathrm{C}$, under a light intensity of $\sim 200 \mu \mathrm{mol}$ photons $\mathrm{m}^{-2} \mathrm{~s}^{-1}$ in a 12-h light/12-h dark period. Reefs at the origin are shallow $(<5 \mathrm{~m}$ depth) and low relief and are better described as coral carpets forming a veneer over a capstone substrate. Sea surface temperatures in this area typically range from $18{ }^{\circ} \mathrm{C}$ in the winter through $36^{\circ} \mathrm{C}$ in the summer, and these reefs have been exposed to recurrent mass bleaching events in the past decade $(1996,1998,2002,2010)$ from which coral communities are continuing to recover (Burt et al. 2008, 2011).

Observations of $P$. lobata in situ were made on colonies in $\sim 1-1.5 \mathrm{~m}$ depth in the reefs in front of the Interuniversity 
Institute for Marine Sciences (IUI), Eilat, Israel, in March 2010. The IUI site $\left(29^{\circ} 30^{\prime} 05^{\prime \prime} \mathrm{N}, 34^{\circ} 55^{\prime} 02^{\prime \prime} \mathrm{E}\right)$ is located in the Gulf of Eilat on the Northern tip of the Red Sea. The sea surface water temperature (SST) is on the rise since 2002, and the average at 2010 was $0.6{ }^{\circ} \mathrm{C}$ higher than the previous year (Shaked and Genin 2011). Secchi depth varies between 18 and $34 \mathrm{~m}$ since 2004 with very little change. The average $\mathrm{pH}$ values varied between 8.17 and 8.25 , while alkalinity has been in the range of $2.5 \pm 0.05 \mathrm{meq} \mathrm{kg}{ }^{-1}$ for the past three years. The currents are stable from the NE to SW with a maximum of $0.3 \mathrm{~m} \mathrm{~s}^{-1}$. The annual mixing of the upper water column with the deeper water of the Gulf of Eilat influences the availability of dissolved inorganic nutrients at the observation site. During the past 2 years, the mixing was very mild due to relatively high air temper atures during the winters. During this time, the partially degraded coral community started a slow recovery of live coral cover.

P. lobata, M. foliosa and A. pulchra collected from Fijian reefs in the regions of Galao Village ( $P$. lobata) and Yanuca Island had been acquired through the aquaristic trade (Tropical Marine Centre, London, UK) in 2008 (M. foliosa and A. pulchra) and 2010 (P. lobata). Acropora polystoma of unconfirmed origin was purchased via the British aquaristic trade in the UK in 2008. The corals were cultured and propagated by fragmentation in the experimental mesocosm of the Coral Reef Laboratory of the NOCS. The corals were kept in artificial sea water (salinity 33 ) at $25^{\circ} \mathrm{C}$, under a light intensity of $\sim 200 \mu \mathrm{mol}$ photons $\mathrm{m}^{-2} \mathrm{~s}^{-1}$ in a 12-h light/12-h dark period. A detailed description of the system is given in D'Angelo and Wiedenmann (2011).

Experimental wounding and sampling

Physical stress was simulated by scratching the surface of $P$. lobata with the tip of a knife or by scraping off the tissue and the upper skeletal layers of replicate colonies of A. pulchra and A. polystoma. After documentation of the wounded areas, the corals were put back to their original place in the holding trays of the experimental mesocosm and left undisturbed for 3 weeks. Afterwards, the corals were photographed again and samples for biomarker analyses were harvested by removing the regenerated tissue using a scalpel. The short-term effects of wounding were documented by a time series of photographs that followed the recovery of experimentally injured A. polystoma. The images of the wound area were taken under a microscope with daylight settings and in the fluorescence mode using the GFP Plus filter set (AHF, Tübingen, Germany), immediately after inflicting damage (day 0) and after 3, 7, 10 and 14 days.
Photographic documentation

Photographs of coral fragments were taken using a digital E500 camera (Olympus, Hamburg, Germany). Daylight pictures were taken using white light illumination. Fluorescence photographs were obtained through a yellow longpass filter (Nightsea, Andover, USA) upon exciting tissue fluorescence with a $\sim 450-n m$ light source (Nightsea, Andover, USA). Details of polyps were photographed with a Leica DFC420C camera fitted to a Leica MZ10 stereomicroscope (Leica Microsystems, Wetzlar, Germany) equipped with CFP/dsRed and GFPplus filtersets (AHF, Tübingen, Germany). The blue channel information of CFP images was transferred to the green channel to match the visual appearance of the coral fluorescence.

Tissue extraction and protein purification

Host tissue extracts were prepared from three replicate colonies as described (Leutenegger et al. 2007b; Oswald et al. 2007). Total protein content was measured using the BCA method (Pierce, Thermo Fisher Scientific, Rockford, USA). GFP-like proteins were purified from the cleared extracts by size-exclusion chromatography using an Aekta Purifier (GE Healthcare, Freiburg, Germany) (Wiedenmann et al. 2002, 2004b). Absorption at the peak wavelength of the GFP-like proteins under study was recorded online during the chromatography runs. GFP-like proteins eluted with apparent molecular weight characteristic for oligomeric representatives of this protein family (Wiedenmann et al. 2002, 2004b, 2005; D'Angelo et al. 2008). Peak fractions were recovered for spectroscopic analysis.

Spectroscopic analysis

Fluorescence spectra were measured on the animal using a Varian Cary Eclipse fluorescence spectrometer (Varian, Palo Alto, USA), equipped with a fibre optic probe as described (D'Angelo et al. 2008). Absorption spectra were recorded from cleared tissue extracts using a Cary absorption spectrometer (Varian). The peak positions of absorption and emission spectra were used to name the pigments. The abbreviation of the species name is followed by the abbreviation CP (non-fluorescent GFP-like chromoprotein) and FP (fluorescent GFP-like protein) and peak position of the absorption (CPs) or emission (FPs) spectrum. For quantification purposes, mean and standard deviation of $>6$ spectra from different colony areas/samples were determined. The significance of the differences in the maximum emission/ absorption was evaluated by two-tailed unpaired $t$ test or Mann-Whitney nonparametric test (apulFP483 and plobFP610) analysis using GraphPad InStat (San Diego, USA). 


\section{RNA preparation and RT-PCR}

We studied the expression of PCNA in M. foliosa and A. pulchra by semi-quantitative reverse transcription polymerase chain reaction (RT-PCR). Total RNA was prepared from the growth zones (branch tips, colony margins) and from inner areas of the colonies. RNA extraction, quality control and analyses were performed as already described (D'Angelo et al. 2008). The sequence of a coral-homolog of PCNA from the EST database of A. millepora (Meyer et al. 2009) was aligned with PCNAs of higher organisms, and primers were designed against conserved regions. Fragments encoding PCNA were amplified from $500 \mathrm{ng}$ cDNA using the primers: PCNA For ( $5^{\prime}$ atgtttgaagcaaagcttacacaaggc $\left.{ }_{3^{\prime}}\right)$ and PCNA Rev ( ${ }_{5}$ catattcttgttctgggatcccaag $\left._{3^{\prime}}\right)$. Transcripts of the housekeeping gene actin were amplified using the primers Actin For $\left({ }_{5}\right.$, ttgctatgttgctcttgacttcg $\left._{3^{\prime}}\right)$ and Actin Rev $\left({ }_{5}{ }^{\prime}\right.$ gatccacatctgttggaaagtagac $\left.{ }_{3^{\prime}}\right)$. PCR conditions and normalization are described in D'Angelo et al. (2008). The intensity of every transcript fragment band was quantified and normalized to the corresponding actin band using MATLAB $^{\circledR}$ (Mathworks, Natick, USA). Mean and standard deviation of four independent samples were calculated, and differences were tested for significance by two-tailed unpaired $t$ test analysis using GraphPad InStat (San Diego, USA). DNA was extracted from the gel bands, and the fragments were cloned in E. coli with the StrataClone cloning kit (Agilent Technologies, Santa Clara, USA). Sequencing of the fragments was performed by a commercial provider (Macrogen, Seoul, Korea). Subsequently, sequences were aligned using Clustal V. PCNA sequences from A. pulchra and M. foliosa were deposited at GenBank (accession numbers: JQ648647; JQ648648).

\section{Measurement of phenoloxidase activity}

Enzymatic activity was determined in protein extracts following a modified version of the protocol by Hauton et al. (1995). First, coral tissue was removed with a scalpel and quickly homogenized in $1 \mathrm{ml}$ prechilled MilliQ-water using a micropestle. Zooxanthellae and skeletal debris were removed by centrifugation $\left(20,000 \mathrm{~g} / 4{ }^{\circ} \mathrm{C} / 10 \mathrm{~min}\right) ; 200 \mu \mathrm{l}$ of the cleared supernatant was saved for the determination of the total protein content by the BCA method (Pierce), and $400 \mu \mathrm{l}$ of the tissue homogenate was mixed with an equal volume of $2 \times$ sodium cacodylate buffer $\mathrm{pH} 7.0$ (20 mM sodium cacodylate, $300 \mathrm{mM}$ sodium chloride, $20 \mathrm{mM}$ hydrated calcium chloride). All solutions were stored on ice during the experiment; $100-\mu \mathrm{l}$ aliquots of the substrate solution (dihydroxyphenylalanine [L-dopa], $4 \mathrm{mg}$ $\mathrm{ml}^{-1}$ freshly prepared in MilliQ-water) were loaded in the required number of cavities of a clear 96-well plate (TPP 96); 200- $\mu$ l aliquots of the processed tissue homogenate
Fig. 1 Expression patterns of GFP-like proteins in growth zones. The green, purple-blue and red hues of $M$. foliosa (a), A. pulchra (f) and $P$. lobata $(\mathbf{k})$ are due to the expression of GFP-like proteins. Microscopic images of the growth zones acquired under white light show the accumulation of chromoproteins (b and $\mathbf{g}$ ) in the colony margins and in the branch tips. The high-level expression of a red fluorescent protein in the margins of $P$. lobata from the Red Sea is visible under daylight conditions (k). Corresponding fluorescence images taken with a CFP/ DsRed filterset show the localization of cyan $(\mathbf{c}, \mathbf{h}, \mathbf{l}-\mathbf{m})$ and red fluorescent (l) proteins. I depicts a $P$. lobata colony originating from Fiji. The fluorescence micrograph in $\mathbf{m}$ shows the view on the underside of a P. lobata colony from the Arabian/Persian Gulf where the colony margin was growing without contact with the substrate. Absorption or emission spectra of the most abundant pigments are depicted: mfolCP577 (d), mfolFP483 (e), apulFP584 (i), apulFP483 (j). plobFP610 (n), plobFP490 (o). Emission spectra were recorded using $420 \mathrm{~nm}(\mathbf{e}, \mathbf{j}$ and $\mathbf{o})$ and $530 \mathrm{~nm}$ light (n) for excitation

were quickly added to each well with substrate solution; 200- $\mu 1$ aliquots of $1 \times$ cacodylate buffer were loaded in the parallel row as background control. The enzyme reaction was followed by measuring the absorption at $492 \mathrm{~nm}$ in an Fluostar Optima plate reader (BMG LABTECH, Ortenberg, Germany) at 5-min intervals. The absorption readings were background-corrected, and the enzyme activity was expressed in arbitrary units representing the increase in absorbance of the sample at $490 \mathrm{~nm}$ over time. The units present in the tissue homogenates were final normalized to the total protein content of the solution. Mean and standard deviation of $\geq 3$ independent samples were calculated, and differences were tested for significance by two-tailed unpaired $t$ test analysis, applying Welch correction in a data set with unequal variances (M. foliosa) using GraphPad InStat (San Diego, USA).

\section{Results}

Spatial expression patterns of GFP-like proteins

To establish GFP-like proteins as intrinsic optical markers of physiological processes in corals, we first characterized their expression patterns in M. foliosa and A. pulchra from Fiji (aquarium-cultured since 2008) and in P. lobata from the Red Sea (field samples), the Arabian/Persian Gulf and Fiji (aquarium-cultured since 2010) (Fig. 1). In all three species, cyan fluorescent proteins with emission maxima ranging from 483 to $490 \mathrm{~nm}$ (Fig. 1e, j, o) were found to be more or less evenly distributed in the light-exposed parts of the colonies. In some Porites specimens, the cyan fluorescence of the polyps was more pronounced compared to the coenosarc, whereas in others both tissue types were equally fluorescent (Fig. 11). Interestingly, in both $M$. foliosa and A. pulchra, the cyan fluorescence in the polyps of the colony margin or branch tips was substantially increased (Fig. 1c, h). Daylight images revealed that these 

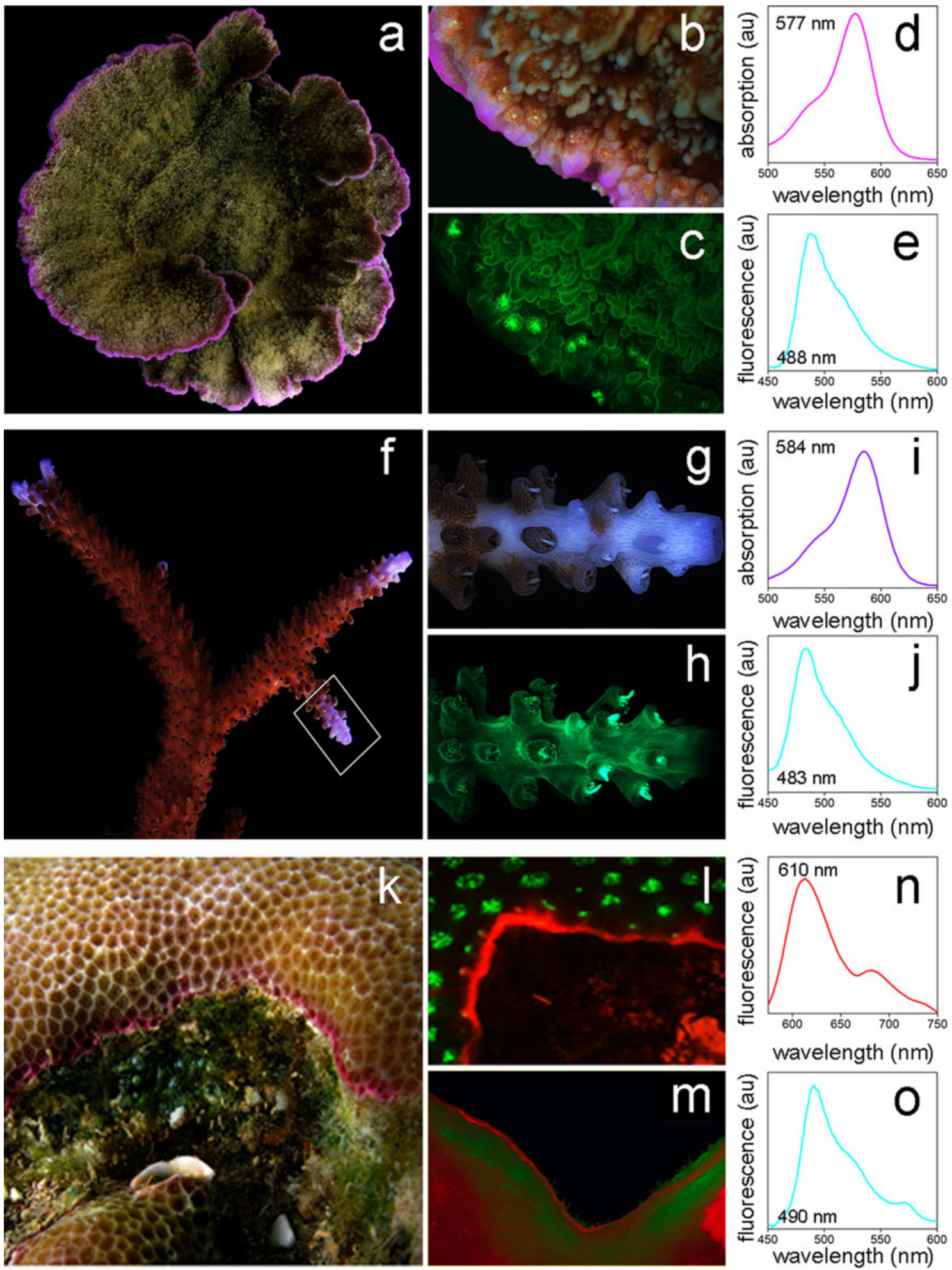

parts of the colonies were strongly coloured due to the presence of the purple chromoprotein mfolCP577 in $M$. foliosa and the violet chromoprotein apulCP584 in $A$. pulchra. In P. lobata from the Red Sea, the Arabian/Persian Gulf and Fiji, the colony margins where the corals extends encrusting over the substrate were characterized by an increased expression of a red fluorescent protein with an emission maximum at $\sim 610 \mathrm{~nm}$ (Fig. $1 \mathrm{k}-\mathrm{m}$ ). Importantly, the elevated expression of plobFP610 can be also observed when the colony margins grow without contact to the 
substrate (Fig. 1m). Therefore, the specific conditions in the growing margin of the colony and not the interactions with the substrate are primarily responsible for the enhanced plobFP610 expression. Zooxanthellae were present only in very low numbers or absent in the pigmented colony tips or margins (Fig. 1b, g).

\section{Biomarkers of coral growth}

To provide evidence for the hypothesis that the specific pigment signatures observed in our model corals are indicative of growing tissue, we studied the expression of the molecular growth marker PCNA. First, we amplified and sequenced a $\sim 400$-bp region of coral PCNAs from $M$. foliosa and A. pulchra. Even in comparison with higher organisms including humans, coral PCNAs appear to be highly conserved (Electronic Supplemental Material, ESM Fig. 1).

Subsequently, we compared the expression levels of PCNA in the strongly pigmented tissue of the growing colony margins of $M$. foliosa to those of the less coloured parts of the inner colony area. Indeed, colony margins showed significantly elevated levels of PCNA transcripts (Fig. 2a).

A previous report noted elevated levels of PO activity in strongly pigmented coral tissue (Palmer et al. 2008); therefore, we tested whether elevated PO levels might be also indicative of growing tissue. Comparing the pigmented growth zones of $M$. foliosa to the established tissue of the inner colony areas, we found a significant increase in $\mathrm{PO}$ activity in growing tissue (Fig. 2b). We note that the $\mathrm{PO}$ activity is independent from the degree of tissue pigmentation as an elevated activity was also found in the growing margin of a $M$. foliosa colour morph that lacked the high-level expression of the purple chromoprotein at the colony edges (ESM Fig. 2).

\section{Colour changes in response to wounding}

We evaluated whether increased growth is the underlying physiological process of the "pink-blue spot syndrome", a colour change linked, for instance, with wounding of Red Sea corals (Bongiorni and Rinkevich 2005). Figure 3a and ESM Figure 3 show examples of the pink-blue syndrome in coral colonies from a reef region frequently accessed by swimmers and divers in Eilat (Israel). To verify that wounding in fact precedes the pink-blue syndrome, we scraped off the tissue from a defined area of laboratorycultured A. pulchra colonies. Within 3 weeks, the damaged areas regenerated and exhibited the bright bluish colour previously observed in damaged corals in the reef (Fig. 3b). Most interestingly, fluorescence microscopic inspection revealed that the polyps in the regenerated area
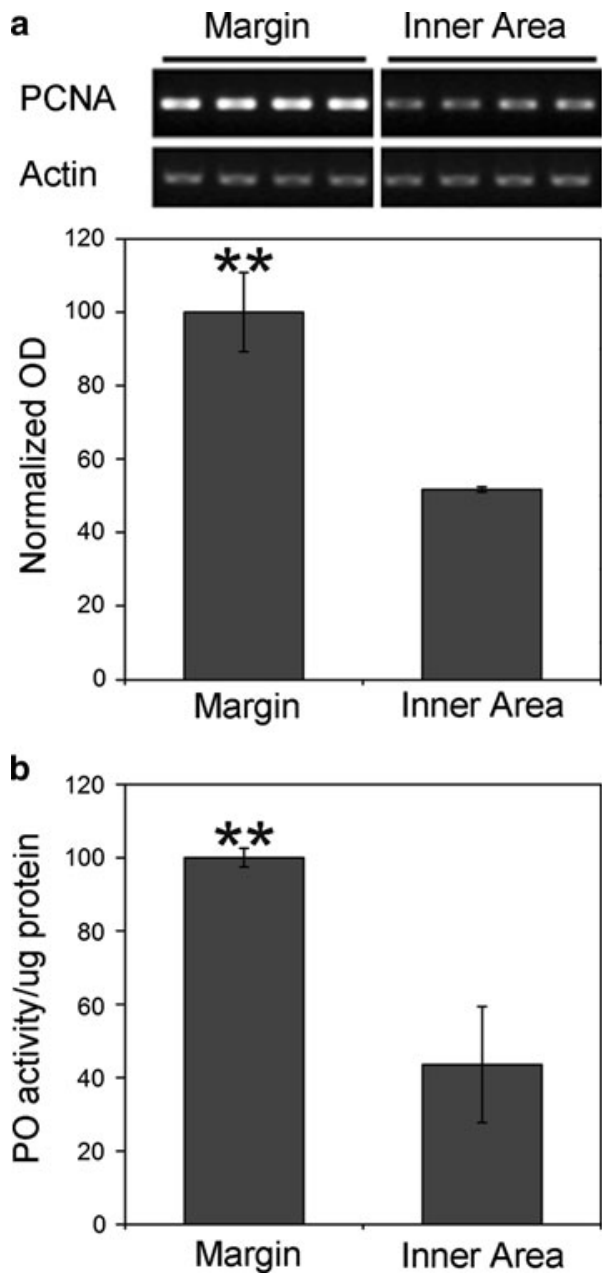

Fig. 2 Biomarkers of coral growth. Semiquantitative RT-PCR analysis of proliferating cell nuclear antigen (PCNA) transcripts in M. foliosa (a). The uppermost panel in (a) shows the bands corresponding to the amplified transcripts visualized on ethidium bromide-stained agarose gels. Transcripts were analysed in animal tissue prepared from growing margins and inner areas of the colonies. The optical density of PCNA bands was normalized to those of the transcript of the host tissue-specific housekeeping gene actin. b Comparison of phenoloxidase (PO) activity normalized to the total protein content of host tissue extracts measured in margins versus inner colony areas of $M$. foliosa. The graphs show the means, and error bars represent standard deviations. Asterisks (**) indicate statistically significant differences with $p<0.01$

showed the increased levels of cyan fluorescence typically observed in the growing tips of this colony (Fig. 3c). A time series of the regeneration process in A. polystoma demonstrates that the blue pigmentation becomes clearly visible $\sim 10$ days post-injury after the wounded tissue has formed smooth margins that grow over the bare skeleton (ESM Fig. 4). To confirm that the colour changes in the regenerating area are indeed indicative of fast proliferating tissue, we analysed the previously established biomarkers in the tissue of A. pulchra after 3 weeks of regeneration. The quantitative and qualitative analyses of GFP-like 
a

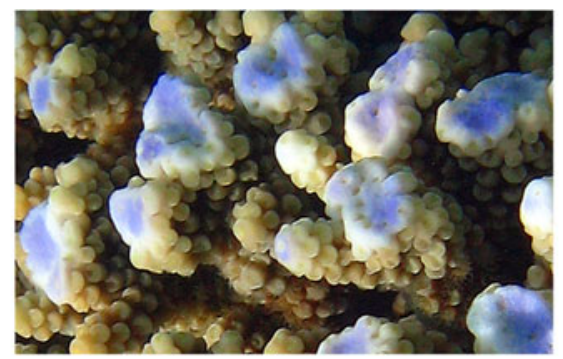

b

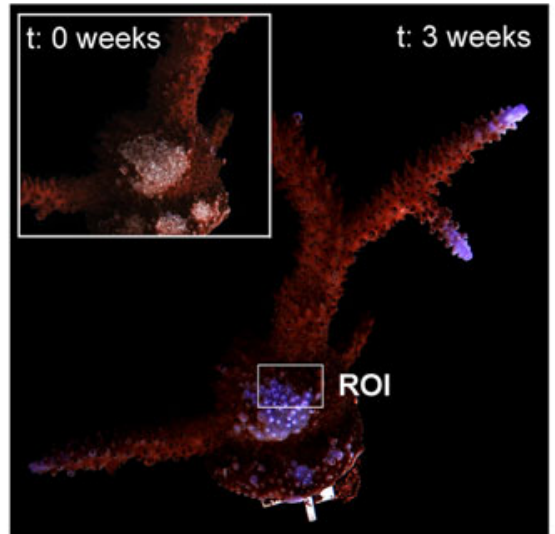

c

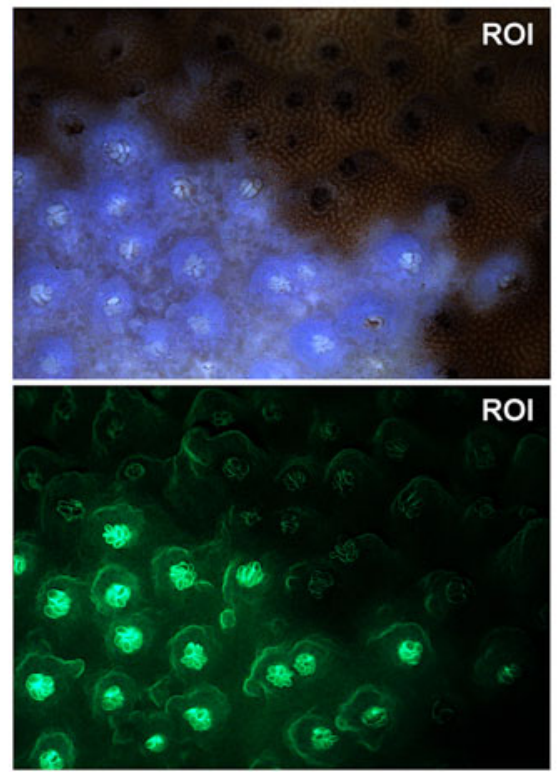

Fig. 3 Biomarker responses to mechanical damage in Acropora sp. a Close-up photograph of Acropora sp. in Gulf of Eilat from an area subject to mechanical disturbances by divers. Inset b A colony of A. pulchra was subjected to mechanical stress by scraping off the tissue at time 0 . The damaged areas appear pale. b After 3 weeks, the damaged areas show intense blue coloration. c The microscopic image shows a close-up of the region of interest (ROI) defined in (b), imaged under daylight illumination (upper panel) and under blue light excitation (lower panel). d apulCP584 and apulFP483 content in the tissue of A. pulchra deduced from absorption/fluorescence readings of gel filtration runs normalized to the total protein content of the sample. e Phenoloxidase activity in branches, tips and regenerating
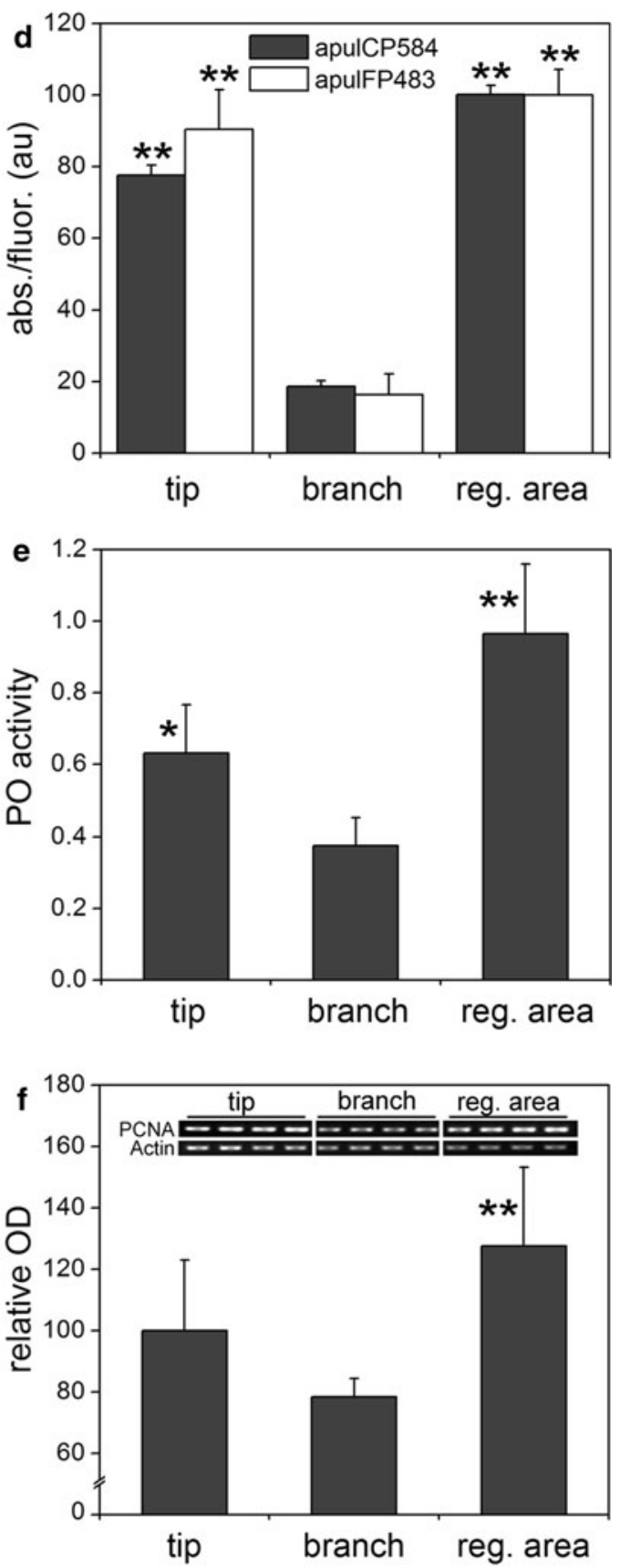

areas normalized to the total protein content of the sample. f PCNA expression in different areas of the A. pulchra colony. The inset shows the amplified transcripts of PCNA and those of the host tissuespecific housekeeping gene actin in ethidium bromide-stained agarose gels. The optical density values of PCNA bands were normalized to those of the actin bands, and the mean values are displayed as bar charts. Error bars indicate standard deviations. Values of tip or regenerating areas were assessed for statistically significant differences in pairwise comparison with the corresponding values of the undisturbed branch area. Asterisks indicate significant differences with $p<0.05(*)$ and $p<0.01(* *)$ 
proteins showed that the expression of both apulCP584 and apulFP483 was significantly upregulated in the regenerating area and the growing tips of the colony compared to undisturbed areas of the branches. Similarly, the expression of PCNA and the PO activity were significantly increased in the regenerating area. Our biomarker analyses show that the specific expression of GFP-like proteins observed in the aftermath of wounding is correlated with enhanced cell proliferation rates in regenerating tissue; notably, also $P$. lobata responded to mechanical damage by displaying the species-specific fluorescence signature of growth areas in the regenerating tissue, namely the increased expression of the red fluorescent protein plobFP610 (ESM Fig. 5).

Colour change phenomena in response to the presence of epibionts

We found a strong increase of red fluorescence in P. lobata in the Red Sea in the presence of the gastropod Coralliophila sp. (ESM Fig. 6), vermetid gastropods (not shown) and the tube worm Spirobranchus sp. (Fig. 4). In the latter case, red fluorescence was most pronounced in the areas where the operculum of Spirobranchus sp. was in contact with the coral and in the tissue surrounding the opening of the tube. The same colonies exhibited also elevated red fluorescence in the growth margin (Fig. 1k), confirming that the local colour change is indicative of enhanced cell proliferation induced by the epibiont. We further analysed the response of $P$. lobata from Fiji to the presence of an unidentified epibiotic crustacean. Most interestingly, the concentration of plobFP610 was increased $>10$-fold in the tissue surrounding corallites inhabited by the single specimen of this crustacean, in comparison with the undisturbed tissue of inner areas of the colony and $\sim 3$-fold compared to the growth margins.

Despite their deviating growth morphology, A. pulchra and $M$. foliosa show a strikingly similar response to the presence of vermetid gastropods (Fig. 5). In both cases, the coral tissue extends over the shells, showing the typical pigment signature of growth areas, namely the accumulation of chromoproteins in the margins and an increased concentration of the cyan fluorescent proteins in the polyps. Cross-sections of the affected tissue areas demonstrate that the shells are not only overgrown by coral tissue, but that
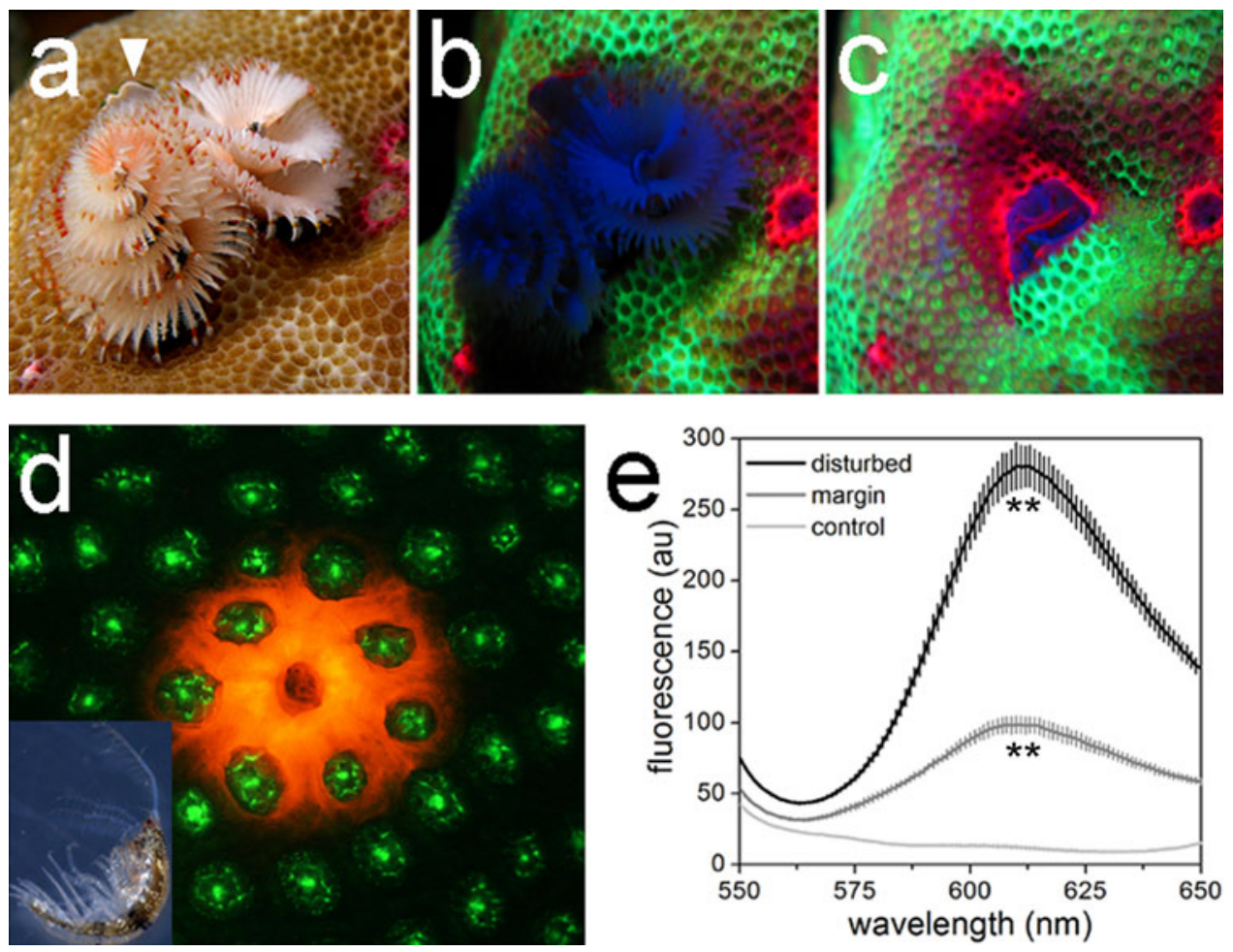

Fig. 4 Localized expression of red fluorescent proteins in Porites sp. a-c Spirobranchus sp. on a Porites colony photographed in the reef of Eilat. Daylight (a) and fluorescence images (b-c) depict the tube worm in its expanded (a-b) and retracted (c) state. Panel $\mathbf{c}$ shows the increased red fluorescence of the tissue areas in contact with the Spirobranchus operculum (indicated by an arrow in a) and around the tube opening. d Microscopic image of localized red fluorescence around a corallite of $P$. lobata inhabited by a unidentified crustacean

(inset) in the experimental mesocosm at NOCS. e Fluorescence spectra recorded in vivo reveal the increase in $\sim 610$-nm emission per area in the infested area in comparison with the growth margins and undisturbed inner areas of the same colony. Mean spectra are shown, and error bars represent standard deviations. Asterisks (**) indicate significant differences with $p<0.01$ in pairwise comparisons between the peak values of the infested area or the growth margin with the corresponding value of the undisturbed inner colony region 
Fig. 5 Expression of GFP-like protein areas in contact with epibionts. Daylight $(\mathbf{a}, \mathbf{d})$ and fluorescence $(\mathbf{b}, \mathbf{e})$ images of M. foliosa and A. pulchra tissue in contact with vermetid gastropods reveal the expression signature of chromoproteins and cyan fluorescent proteins typical for growth zones. Crosssections of the affected colony parts show the encapsulation of the gastropod shells by coral skeleton
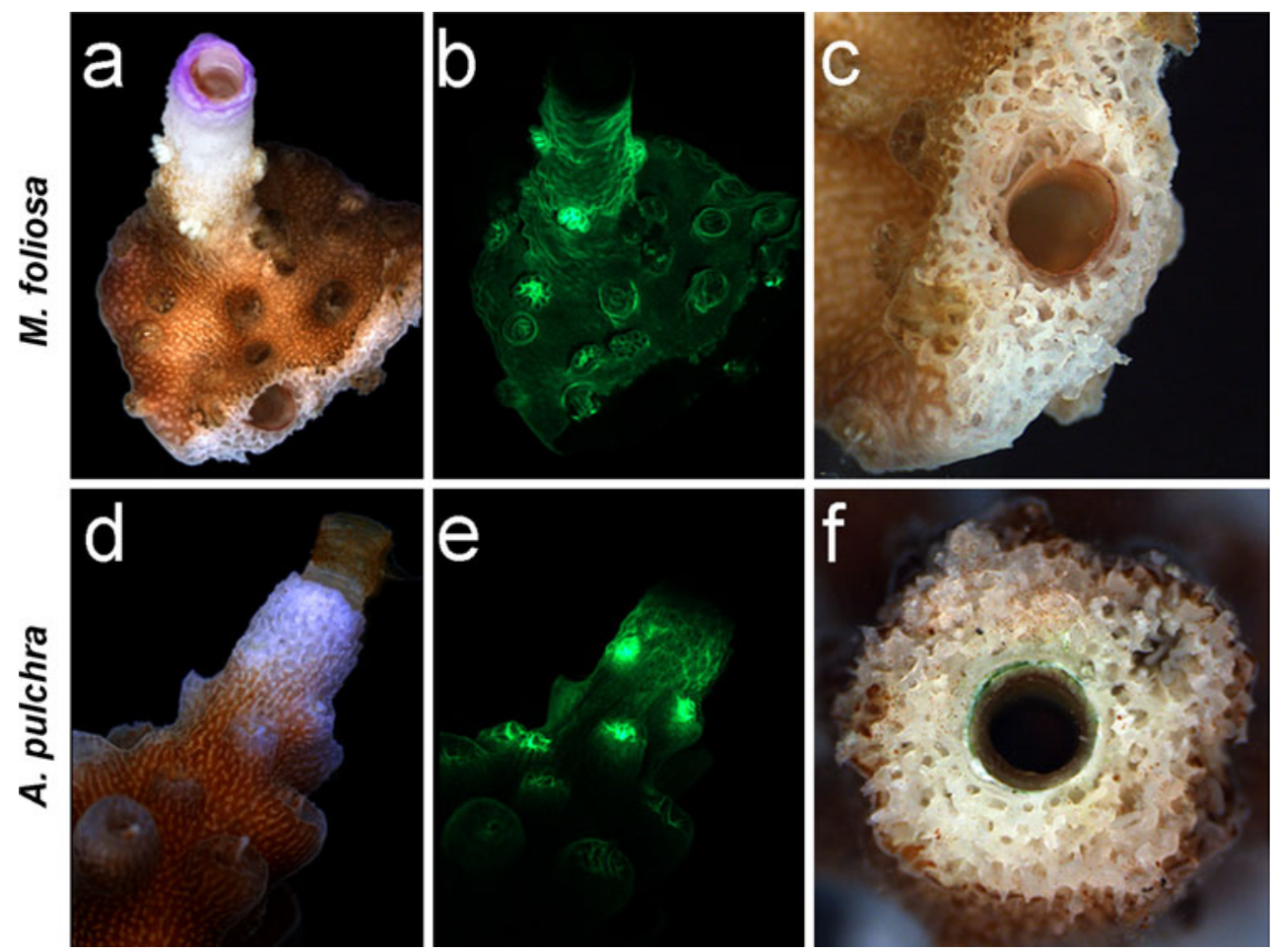

also skeletal material is deposited on them, highlighting the potential for permanent encapsulation of xenobionts.

\section{Discussion}

Development of biomarkers for coral growth

\section{PCNA}

The alignment of amino acid sequences revealed that coral PCNAs are highly conserved even in comparison with higher organisms including humans (ESM Fig. 1). Hence, it is reasonable to assume that PCNA fulfils the same function in the dividing coral cells as it does in higher organisms, namely to act as processivity factor for DNA polymerase during replication of the chromosomes (Strzalka and Ziemienowicz 2011). As expected, the expression of PCNA was increased in growing colony parts such as the margins of $M$. foliosa.

\section{Phenoloxidase}

Elevated PO activity levels were previously found in nonnormally pigmented tissue of A. millepora and were linked to a potential immune response of corals (Palmer et al. 2008). Here, we show that a significantly increased PO activity can be found in growing colony parts such as margins or branch tips in both M. foliosa and A. pulchra. PO activity was increased not only in growth zones that showed elevated expression levels of GFP-like proteins, but also in the colony margins of the brown M. foliosa morph, which does not accumulate detectable levels of GFP-like proteins. The consistent increase in PO activity in growth zones makes this enzyme a promising biomarker of coral growth, although its function in newly formed tissue needs to be further investigated. Alternatively to providing immune protection, PO might fulfil other or additional functions in corals.

\section{GFP-like proteins}

We found an increased expression of GFP-like proteins in the growth zones of coral species which was independent from the colony morphologies (plate-like vs. branching vs. massive) and consistent over a wide geographical range ( $P$. lobata). The specific pigmentation patterns of the growth zones were correlated with an enhanced expression of PCNA and increased PO activity. Therefore, distinct GFPlike proteins are suitable to identify areas of growth and accelerated cell proliferation. They are particularly powerful as biomarkers as they can be quickly identified and quantified by non-invasive optical techniques. However, the types of GFP-like proteins that are upregulated in the 
growth zones might vary between some species, and the specific FP/CP biomarker pattern needs to be established for each species and reef area under study.

Corals and other anthozoans exhibit pronounced colour polymorphisms that result from differences in the maximal expression level of GFP-like proteins (Field et al. 2006; Leutenegger et al. 2007b; Oswald et al. 2007). These colour polymorphisms can also affect the growth zones as demonstrated by our analysis of the brown morph of $M$. foliosa with non-pigmented growth margins, indicating that a high-level expression of GFP-like proteins is not a functional prerequisite for growth.

However, the lack of high-level expression in some corals does not seriously affect applicability of the approach to use GFP-like proteins as intrinsic biomarkers as the great majority of corals express fluorescent pigments (Salih et al. 2000). Thus, a plethora of species for which the modulation of FP/CP expression patterns could be established might potentially be utilized as indicator species for certain physiological processes.

In line with previous studies, zooxanthellae were present only in very low numbers or absent in the pigmented colony tips or margins (Fang et al. 1989; D'Angelo et al. 2008). In the growth zones, the weak absorption of the incident light by the low amounts of photosynthetic zooxanthellae pigments results in an increased reflection by the skeleton. The resulting amplification of the internal light intensity in the coral tissue (Terán et al. 2010) presumably induces a lightdriven upregulation of GFP-like protein genes (D'Angelo et al. 2008). We hypothesize that the strong accumulation of GFP-like proteins in the growth zones provides enhanced photoprotection for zooxanthellae that need to colonize areas exposed to increased levels of light stress.

\section{Application of biomarkers to study colour anomalies} in corals

We tested whether the pink/blue spot syndrome (Bongiorni and Rinkevich 2005), which is often observed among Red Sea corals, for instance, in response to wounding, might be indicative of growth processes. Indeed, in A. pulchra, the newly regenerated tissue in the area of experimental wounding showed an increased expression of apulCP584 in the coenosarc and of apulFP483 in the polyps, the expression pattern typical for tissue of growing branch tips in this species. Together with significantly increased PCNA expression and elevated PO activity, our data suggest that the non-normal pigmentation of the pink/blue spot syndrome is indicative of increased cell proliferation associated with tissue regeneration. The regenerating areas of experimentally damaged $P$. lobata also showed an increased accumulation of a GFP-like protein (plobFP610) that is otherwise found in the growth margins of the colonies, suggesting that the pigmentation response can be found over a broad taxonomic range. The conspicuous pink coloration of the healing edges in Porites sp. recovering after experimental injury in the field further underlined the universal character of this response (van Woesik 1998). Taken together, the comparison of expression patterns of GFP-like proteins between growth zones and unusually pigmented areas elsewhere in the colony enables the identification of regions of increased cell proliferation and tissue growth. In agreement with the previous interpretations of comparable colour changes in reef corals (Bongiorni and Rinkevich 2005; Beeden et al. 2008), our data show that the pink/blue spot syndrome represents a response of healthy corals to local challenges.

Locally accelerated growth as part of the corals' innate immune response

Epibionts such Spirobranchus sp. or vermetid snails induce the expression of growth-specific patterns of GFP-like proteins in P. lobata, A. pulchra and M. foliosa, indicating that the presence of the xenobiont accelerates the growth rates of the surrounding coral tissue. Assuming a quantitative relationship between the growth-specific expression of GFP-like proteins and the proliferation rate of the tissue, the strongly increased fluorescence suggests that the presence of foreign organisms in $P$. lobata results in growth rates that exceed those in the regular growth zones such as the colony margins.

The accelerated growth in the presence of foreign biological material represents a novel component of the innate immune response of reef corals in which the animals try to neutralize potentially dangerous xenobionts by overgrowing them. Encapsulation is a common part of the cellular immune response in arthropods (Gillespie et al. 1997) during which non-self particles are recognized and engulfed in a capsule of aggregating hemocytes. The encapsulation response of corals can be viewed as an analogous process at the macroscopic scale. This process explains the "swelling" of highly pigmented Porites tissue in contact with Coralliophila sp. or the formation of nodules around encysted trematodes (Oren et al. 1998; Aeby 2003) as attempts of the coral to neutralize xenobionts by encapsulation (ESM Fig. 6).

Implications for coral reef monitoring and survival

The future of coral reefs is strongly dependent on management strategies that can promote their recovery and resilience. The success of these efforts will markedly rely on the identification of particularly vulnerable areas or regions affected by high levels of stress. (Marshall and Schuttenberg 2006). The spectral analysis of fluorescence 
signatures of indicator corals represents a non-invasive, fast and low cost method to assess stress levels in coral reef communities. Using specific GFP-like proteins as biomarkers, we identified locally accelerated growth as part of the corals' innate immune response that aims to neutralize xenobionts by encapsulation. Furthermore, unusual host pigmentation can be indicative of tissue regeneration processes. In the context of coral reef monitoring, these colour changes can be used as indicators of mechanical stress/ damage inflicted, for instance, by swimmers or divers or give an indication of the load of epibionts/parasites (Bongiorni and Rinkevich 2005). The detailed characterization of the specific response of coral pigmentation to perturbations provided here will help to establish coral host colour as a cumulative indicator of physiological processes.

A downregulation of particular FP-encoding transcripts was previously reported, for instance, in response to heat stress, strong irradiation, bleaching and translocation (Dove et al. 2006; Leutenegger et al. 2007a; D'Angelo et al. 2008; Bay et al. 2009). The distinct response of several FP genes to various changes in the environmental conditions suggests that further biomarker assays can be developed that employ these pigments as the urgently needed intrinsic markers of coral health (D'Angelo et al. 2008).

Acidification, warming and eutrophication of the oceans will likely slow down coral growth rates in the future (Hoegh-Guldberg et al. 2007). This might result in a reduced capability of the corals to defend themselves against xenobiont colonization, yet another potentially detrimental consequence of altered environmental conditions on coral reefs.

Acknowledgments The study was funded by NERC (NE/I01683X/1 \& NE/I012648/1 to JW; studentship to EGS), DFG (Wi1990/2-1 to JW) and ASSEMBLE (to JW \& DT). Our appreciation is extended to A. Al-Hemeri of the UAE Federal Environment Agency and A. AlCibahy of the Environment Agency of Abu Dhabi for provision of CITES export permits (No. 09FEA555) for UAE corals. We are grateful to staff and students of Interuniversity Institute for Marine Science (Eilat) for field work support and to Dr. Chris Hauton (NOCS) for discussions about the phenoloxidase assays. We acknowledge Tropical Marine Centre (London, UK) and Tropic Marine (Wartenberg, Germany) for sponsoring of the Coral Reef Laboratory at NOCS.

Open Access This article is distributed under the terms of the Creative Commons Attribution License which permits any use, distribution, and reproduction in any medium, provided the original author(s) and the source are credited.

\section{References}

Aeby GS (2003) Corals in the genus Porites are susceptible to infection by a larval trematode. Coral Reefs 22:216

Aeby GS, Williams GJ, Franklin EC, Kenyon J, Cox EF, Coles S, Work TM (2011) Patterns of coral disease across the Hawaiian
Archipelago: Relating disease to environment. PLoS One 6:e20370

Alieva NO, Konzen KA, Field SF, Meleshkevitch EA, Hunt ME, Beltran-Ramirez V, Miller DJ, Wiedenmann J, Salih A, Matz MV (2008) Diversity and evolution of coral fluorescent proteins. PLoS One 3:e2680

Bay LK, Ulstrup KE, Nielsen HB, Jarmer H, Goffard N, Willis BL, Miller DJ, Van Oppen MJ (2009) Microarray analysis reveals transcriptional plasticity in the reef building coral Acropora millepora. Mol Ecol 18:3062-3075

Beeden R, Willis BL, Raymundo LJ, Page CA, Weil E (2008) Underwater cards for assessing coral health on Indo-Pacific reefs. Currie Communications. Melbourne, Australia, pp 1-26

Benzoni F, Galli P, Pichon M (2010) Pink spots on Porites not always a coral disease. Coral Reefs 29:153

Bongiorni L, Rinkevich B (2005) The pink-blue spot syndrome in Acropora eurystoma (Eilat, Red Sea): A possible marker of stress? Zoology 108:247-256

Burt J, Bartholomew A, Usseglio P (2008) Recovery of corals a decade after a bleaching event in Dubai, United Arab Emirates. Mar Biol 154:27-36

Burt J, Al-Harthi S, Al-Cibahy A (2011) Long-term impacts of coral bleaching events on the world's warmest reefs. Mar Environ Res 72:225-229

Cooney RP, Pantos O, Tissier MDAL, Barer MR, O'Donnell AG, Bythell JC (2002) Characterization of the bacterial consortium associated with black band disease in coral using molecular microbiological techniques. Environ Microbiol 4:401-413

D’Angelo C, Denzel A, Vogt A, Matz MV, Oswald F, Salih A, Nienhaus GU, Wiedenmann J (2008) Blue light regulation of host pigment in reef-building corals. Mar Ecol Prog Ser 364:97-106

D’Angelo C, Wiedenmann J (2011) An experimental mesocosm for long-term studies of reef corals. J Mar Biol Assoc UK 92:769-775

Dove SG, Hoegh-Guldberg O, Ranganathan S (2001) Major colour patterns of reef-building corals are due to a family of GFP-like proteins. Coral Reefs 19:197-204

Dove S, Ortiz JC, Enriquez S, Fine M, Fisher P, Iglesias-Prieto R, Thornhill D, Hoegh-Guldberg O (2006) Response of holosymbiont pigments from the scleractinian coral Montipora monasteriata to short-term heat stress. Limnol Oceanogr 51:1149-1158

Fang L-S, Chen Y-WJ, Chen C-S (1989) Why does the white tip of stony coral grow so fast without zooxanthellae? Mar Biol 103:359-363

Field SF, Bulina MY, Kelmanson IV, Bielawski JP, Matz MV (2006) Adaptive evolution of multicolored fluorescent proteins in reefbuilding corals. J Mol Evol 62:U315-332

Fuchs J, Böhme S, Oswald F, Hedde PN, Krause M, Wiedenmann J, Nienhaus GU (2010) Imaging protein movements in live cells with super-resolution using mIrisFP. Nat Methods 7:627-630

Gillespie JP, Kanost MR, Trenczek T (1997) Biological mediators of insect immunity. Annu Rev Entomol 42:611-643

Gladfelter WB (1982) White-band disease in Acropora palmata: Implications for the structure and growth of shallow reefs. Bull Mar Sci 32:639-643

Hauton C, Hawkins LE, Williams JA (1995) Circatidal rhythmicity in the activity of the phenoloxidase enzyme in the common shore crab, Carcinus maenas. Comp Biochem Physiol, Part B: Biochem Mol Biol 111:347-352

Hoegh-Guldberg O, Mumby PJ, Hooten AJ, Steneck RS, Greenfield P, Gomez E, Harvell CD, Sale PF, Edwards AJ, Caldeira K, Knowlton N, Eakin CM, Iglesias-Prieto R, Muthiga N, Bradbury RH, Dubi A, Hatziolos ME (2007) Coral reefs under rapid climate change and ocean acidification. Science 318:1737-1742 
Hughes TP, Baird AH, Bellwood DR, Card M, Connolly SR, Folke C, Grosberg R, Hoegh-Guldberg O, Jackson JBC, Kleypas J, Lough JM, Marshall P, Nystroem M, Palumbi SR, Pandolfi JM, Rosen B, Roughgarden J (2003) Climate change, human impacts, and the resilience of coral reefs. Science 301:929-933

Kredel S, Oswald F, Nienhaus K, Deuschle K, Röcker C, Wolff M, Heilker R, Nienhaus GU, Wiedenmann J (2009) mRuby, a bright monomeric red fluorescent protein for labeling of subcellular structures. PLoS One 4:e4391

Leonardi E, Girlando S, Serio G, Mauri FA, Perrone G, Scampini S, Dalla Palma P, Barbareschi M (1992) PCNA and Ki67 expression in breast carcinoma: correlations with clinical and biological variables. J Clin Pathol 45:416-419

Leutenegger A, Kredel S, Gundel S, D'Angelo C, Salih A, Wiedenmann J (2007a) Analysis of fluorescent and non-fluorescent sea anemones from the Mediterranean Sea during a bleaching event. J Exp Mar Biol Ecol 353:221-234

Leutenegger A, D'Angelo C, Matz MV, Denzel A, Oswald F, Salih A, Nienhaus GU, Wiedenmann J (2007b) It's cheap to be colorful. Anthozoans show a slow turnover of GFP-like proteins. FEBS J 274:2496-2505

Marshall PA, Schuttenberg HZ (2006) A reef manager's guide to coral bleaching. Great Barrier Reef Marine Park Authority, Australia

Meyer E, Aglyamova GV, Wang S, Buchanan-Carter J, Abrego D, Colbourne JK, Willis BL, Matz MV (2009) Sequencing and de novo analysis of a coral larval transcriptome using 454 GSFlx. BMC Genomics 10:219

Nienhaus GU, Wiedenmann J (2009) Structure, dynamics and optical properties of fluorescent proteins: perspectives for marker development. ChemPhysChem 10:1369-1379

Oren U, Brickner I, Loya Y (1998) Prudent sessile feeding by the corallivore snail, Coralliophila violacea on coral energy sinks. Proc R Soc Lond, Ser B: Biol Sci 265:2043-2050

Oswald F, Schmitt F, Leutenegger A, Ivanchenko S, D'Angelo C, Salih A, Maslakova S, Bulina M, Schirmbeck R, Nienhaus GU, Matz MV, Wiedenmann J (2007) Contributions of host and symbiont pigments to the coloration of reef corals. FEBS J 274:1102-1109

Palmer CV, Mydlarz LD, Willis BL (2008) Evidence of an inflammatory-like response in non-normally pigmented tissues of two scleractinian corals. Proc R Soc Lond, Ser B: Biol Sci 275:2687-2693

Prescott M, Ling M, Beddoe T, Oakley AJ, Dove S, Hoegh-Guldberg O, Devenish RJ, Rossjohn J (2003) The $2.2 \AA$ crystal structure of a pocilloporin pigment reveals a nonplanar chromophore conformation. Structure 11:275-284

Ravindran J, Raghukumar C (2006) Pink-line syndrome, a physiological crisis in the scleractinian coral Porites lutea. Mar Biol 149:347-356

Rosenberg E, Loya Y (eds) (2004) Coral health and disease. Springer, Berlin

Salih A, Larkum A, Cox G, Kuhl M, Hoegh-Guldberg O (2000) Fluorescent pigments in corals are photoprotective. Nature 408:850-853

Shaked Y, Genin A (2011) The Israel National Monitoring Program at the Northern Gulf of Aqaba. Ministry of environmental protection, State of Israel, Scientific report 2010

Strzalka W, Ziemienowicz A (2011) Proliferating cell nuclear antigen (PCNA): a key factor in DNA replication and cell cycle regulation. Ann Bot 107:1127-1140

Terán E, Méndez ER, Enríquez S, Iglesias-Prieto R (2010) Multiple light scattering and absorption in reef-building corals. Appl Opt 49:5032-5042

van Woesik R (1998) Lesion healing on massive Porites spp. corals. Mar Ecol Prog Ser 164:213-220

Wiedenmann J, Röcker C, Funke W (1999) The morphs of Anemonia aff. sulcata (Cnidaria, Anthozoa) in particular consideration of the ectodermal pigments. Verhandlungen der GfÖ 29:497-503

Wiedenmann J, Schenk A, Röcker C, Girod A, Spindler KD, Nienhaus GU (2002) A far-red fluorescent protein with fast maturation and reduced oligomerization tendency from Entacmaea quadricolor (Anthozoa, Actinaria). Proc Natl Acad Sci USA 99:11646-11651

Wiedenmann J, Ivanchenko S, Oswald F, Nienhaus GU (2004a) Identification of GFP-like proteins in nonbioluminescent, azooxanthellate Anthozoa opens new perspectives for bioprospecting. Mar Biotechnol 6:270-277

Wiedenmann J, Ivanchenko S, Oswald F, Schmitt F, Röcker C, Salih A, Spindler KD, Nienhaus GU (2004b) EosFP, a fluorescent marker protein with UV-inducible green-to-red fluorescence conversion. Proc Natl Acad Sci USA 101:15905-15910

Wiedenmann J, Vallone B, Renzi F, Nienhaus K, Ivanchenko S, Röcker C, Nienhaus GU (2005) Red fluorescent protein eqFP611 and its genetically engineered dimeric variants. J Biomed Opt 10:14003

Wiedenmann J, Oswald F, Nienhaus GU (2009) Fluorescent proteins for live cell imaging: opportunities, limitations, and challenges. IUBMB Life 61:1029-1042 